\title{
Erratum: Transfer line scattering model of therapeutic hadron beams and applications to nozzle and gantry optimization \\ [Phys. Rev. ST Accel. Beams 16, 014702 (2013)]
}

\author{
M. Palm, M. Benedikt, and U. Dorda \\ (Received 20 February 2013; published 6 March 2013)
}

DOI: $10.1103 /$ PhysRevSTAB.16.039901

PACS numbers: 87.55.tg, 79.20.Rf, 99.10.Cd

The authors of the paper [1] wish to add references on the proton gantry design shown in Fig. 6 of this paper. The MedAustron proton gantry is a hardware copy of this state-of-the-art Gantry 2, designed and developed by the Paul Scherrer Institute (PSI) [2,3]. The authors wish to express their appreciation and gratitude for the expertise and support provided by PSI within the collaboration with MedAustron.

[1] M. Palm, M. Benedikt, and U. Dorda, Phys. Rev. ST Accel. Beams 16, 014702 (2013).

[2] E. Pedroni, D. Meer, C. Bula, S. Safai, and S. Zenklusen, Eur. Phys. J. Plus 126, 66 (2011).

[3] E. Pedroni et al., Z. Med. Phys. 14, 25 (2004).

Published by the American Physical Society under the terms of the Creative Commons Attribution 3.0 License. Further distribution of this work must maintain attribution to the author(s) and the published article's title, journal citation, and DOI. 